\title{
Defending Backwards Causation against the Objection from the Ignorance Condition
}

\author{
Abla Hasan \\ University of Nebraska-Lincoln \\ BIBLID [0873-626X (2014) 39; pp. 173-197]
}

\begin{abstract}
Since Michel Dummett published "Can an effect precede its cause?" (1954), in which he argued for the logical consistency of backwards causation, the controversial concept has turned to a subject of all kinds of interpretations and misinterpretations. Some like Ben-yami, Peijnenburg and Gorovitz have wrongly ascribed to Dummett the view that the argument for the consistency of believing in backwards causation applies only in cases where the agent doesn't know about the occurrence of the past effect. In this paper I defend Dummett's argument by clearing up the confusion caused by ascribing the ignorance condition to Dummett.
\end{abstract}

\section{Keywords}

Cause, effect, backwards causation, ignorance condition, logical consistency

First, let me explain what I mean by the ignorance condition. The ignorance condition is the thesis that the agent needs to be ignorant of the occurrence of the past event to have a good reason to consistently believe that bringing about that event by doing something in present makes sense.

Ben-Yami in his paper "The impossibility of backwards causation" argues that Dummett's condition can't be fulfilled and consequentially makes the argument for backwards causation impossible. BenYami says, 
Dummett acknowledged the difficulty which the bilking argument creates for the possibility of backwards agent-causation. He presents the argument and tries to reply to it on pp.352-8 of "Bringing about the Past". His conclusion is that for backwards agent-causation "to make sense" the agents should be incapable of knowing whether the earlier event, which they are now trying to cause, has occurred (Ben-Yami 2007: 446)

Therefore, in his argument against the coherence of backwards causation Ben-Yami uses cases where the agent's knowledge of the occurrence of the past event seems to be separable from the agent's intention to bring about that type of event. He says, "specifically, we need to assume that any alleged cause can be prevented if agents know that b [the young men have been brave] has occurred" (BenYami 2007: 443).

He puts his conclusion as the following

I have thus shown that one of the conditions Dummett finds necessary for an agent's action to produce an effect, namely, that the agent cannot know, at the time of the action, whether the effect has occurred, makes it impossible for the case to be one of backwards causation. (Ben-Yami 2007: 455)

The same view, that ascribes to Dummett the belief in the ignorance condition as a condition for the consistency of backwards causation, appears also in Jeanne Peijenburg's paper "Shaping your own life". She says, "Dummett's argument implies that something did happen in the past, and on condition that we do not know what it is, we are able to exert some influence" (Peijnenburg 2006: 245). Similarly, we find Gorovitz arguing for the agent's ignorance as a condition for Dummett's argument. He states,

In his earlier article [Dummett] on reverse causality, he suggests that the causal connections that work in reverse are effective only in cases where the agent is ignorant of whether or not the desired event has actually occurred. (Gorovitz 1964: 369)

However, this condition, i.e., the ignorance condition, is not required by Dummett in the first place and ascribing this condition to Dummett is a misinterpretation of his argument. Therefore in this paper I clarify the misinterpretation by explaining Dummett's position on the ignorance condition. I argue that, for Dummett, the agent's ignorance of the occurrence of past events is not a condition 
for the consistency of believing that the causes for those past events can be located in the present. Therefore, reading Dummett as requiring the ignorance condition as a condition for his argument for the logical consistency of backwards causation is a misinterpretation.

But first, and in order to be able to fully appreciate Dummett's view on the ignorance condition, we need to understand what both the concept of the past and the concept of the future mean for Dummett; more importantly speaking, what do our knowledge of the past and our knowledge of the future refer to? According to Dummett, we have two kinds of knowledge: knowledge of the future and knowledge of the past. Our knowledge of the future can be analyzed into: "prediction based on causal laws and knowledge in intention" (Dummett 1980: 344). Our knowledge of the future as based on prediction can be something like my knowledge that it might rain tomorrow, as I observe the cloudy sky this evening. This kind of knowledge is simple and based on causal laws. In addition, there is my knowledge of the future as based on intention; for example I know that the door will be opened after five minutes because I intend to open the door after five minutes. On the other hand, Dummett believes our knowledge of the past to be based on our memories and on deductions from the present. Dummett says, "with our knowledge about what has happened in the past, it is quite different: we have our memories, and we also have deductions from what is the case now, based upon our belief in certain causal regularities" (Dummett 1980: 331). I might for example know that my precious vase was broken yesterday because I remember seeing it falling on the floor and smashing into pieces; this kind of knowledge is based on my own observation, which can be preserved by the aid of memory. But in addition, I might know things about the past without personally observing them taking place in the past; this is what Dummett refers to as the knowledge of the past as based on deductions from the present: here comes the role of the causal laws again, because I can know for example that it has rained yesterday from observing the wet yard as I wake up in the morning and without really the need to observe it raining.

What Dummett rightly observes is that knowledge in intention has no parallel in the case of our knowledge of the past, because while we take knowledge in intention as a sufficient way to know about fu- 
ture we don't similarly appeal to our knowledge in intention when it comes to our knowledge of the past; this takes place mainly because we are beings that have memory but don't have foreknowledge. I don't have to appeal to my knowledge in intention as applied to past events the way I appeal to it when it comes to future events, because I can always know about the occurrence of past events via what my memory tells me in cases of my own observations, and what others' memories can tell me in cases of depending on others' testimony.

But what if we had foreknowledge? Dummett asks; then, the picture would be the same for both cases of future as well as for the past. Then we would not trust our knowledge in intention as directed to the future the way we trust it now, and we would prefer knowledge based on our foreknowledge faculty the way we prefer now knowledge based on our memory. Then it would be difficult to form intentions directed to the future in the way we now find it difficult to form intentions directed to the past. Dummett says, "For us to be able to form future intentions at all, we should have to have a cognitive attitude to the future not wholly analogous to our present attitude to the past" (Dummett 1996: 362).

This difference, i.e., between having memory and not having foreknowledge, is of great importance when it comes to the way we form our causal beliefs towards the future or towards the past. We have a special faculty that enables us to know what has happened and to say for sure that what has happened has happened: this faculty is memory. But when it comes to the future we don't have, as human beings, a similar faculty that we can trust to inform us about what will happen in the way we can trust what our memories tell us about what has happened. Now, the consequence of not having foreknowledge but having memory is that we don't feel that knowledge in intention can be applicable in the case of knowing the past in the way it can be applicable in the case of knowing the future, because we have ways to know about the past other than via knowledge in intention. Therefore, when we are informed about the nonoccurrence of past events by the ordinary ways of being informed, we usually take their nonoccurrence for granted even if those types of events are in our power to bring about by doing something in the present.

In other words, if the agent is informed by the ordinary ways of being informed about the nonoccurrence of a past event and he had 
the present intention to bring about that event which is in his power to be brought about, he will take the nonoccurrence of that past event as granted but he will take a different attitude if he is informed about the nonoccurrence of a future event that he intends to bring about by doing something, because he will trust his knowledge in intention in the case of the future but will hesitate to do the same in the case of the past event.

Let's take a simple example. Suppose that I have recently moved with my family to a new house. The landlord provides us with some keys but then he warns us that some of those keys might not really work properly. As he gives us all three keys, he tells us that he can't really identify which ones might not be working because he doesn't have the time to try all of them and because we can simply know by way of trying which ones do not work. However, I get my key and I give the other two to my husband and my son. Suppose that like our landlord we didn't have the time to try the three different keys we have got. But as I return from work and I try my key and it works perfectly, I know that mine is working. For a couple of days I keep using my key to open the door with no problems at all. The next week my son calls me to say that his key which he is using for the first time is not working and he tells me furthermore that we need to call the landlord because the door can never be opened unless he provides us with extra keys. What would be my response in this case? Simply, I will assure my son that I am on the way and that there is no need to call the landlord, because I have my keys. Now, the question is how do I know that the door will be opened? The answer is because of my knowledge in intention as applied to the future.

I can know and even assure my son that the door will be opened after I arrive, because I have the intention to open the door by using my key when I arrive. In other words, my belief in the opening of the front door lies in my intention to open the front door. Let's suppose that my son called me on the phone to tell me that he came home yesterday and couldn't open the front door by using his key. In this case I don't have any way to know about what has happened other than my son's testimony; because his testimony provides me with knowledge based on his memory. Appealing to knowledge in intention is not even an option when we have knowledge based on memory, because we have memory but we don't have foreknowledge. By depending on 
our memory - excluding cases of hallucinations and being unable to recall what has taken place - we believe we can know what has happened for sure, and therefore appealing to knowledge in intention seems superfluous and even awkward. In the previous example, when my son tells me that he couldn't open the door yesterday, I take the truth of what he is saying for granted. His testimony would be in this case the most reliable way to know what has happened when he tried to open the door. But, when he calls me to tell me that the door can't be opened today, I can appeal to my intention to use my key to open the door to believe that, contrary to what my son is reporting, the door will be opened today, because I intend to open the door after arriving.

In the previous example, I know that the door will be opened because I believe that I have the working keys and this can be sufficient to open the door. But let's suppose that I arrived at the house and this time, unlike all the other times I tried my keys, the door didn't open. Suppose that the reason for the door not to be opened was different from what both my son and I have suspected. Suppose that both our keys are working, but, because of my son's wrong attempts to open the door, the lock of the door has been damaged from the inside. In this case, although I had a reason to believe that the door will be opened because of my intention to open the door, my knowledge in intention, one way I have to know about the future, was proven not to be as reliable as our ordinary ways of knowing about the past.

In short, we apply knowledge in intention to know the future because we have memory but we don't have foreknowledge. The reliability of the other ways we have of knowing about the past makes us eliminate knowledge in intention as a way to know the past. However this doesn't lead Dummett to eliminate knowledge in intention as a considerable way to think of the past under certain conditions that he describes. Before we go through those conditions, what seems of a great importance in order to be able to understand Dummett's position on the ignorance condition is to distinguish two ways of being informed about the occurrence of events in the future or in the past. First, there is knowledge in intention; and second, there is knowledge as acquired by ordinary ways of being informed. Now, in the case of the future, ordinary ways of being informed in addition to knowledge in intention are knowledge as based on predications 
from the present, while in the case of the past, ordinary ways of being informed are deductions from the present and what memory can tell us.

Now, the important step that Dummett takes is viewing knowledge in intention as being applicable in principle to the past in the way it can be applicable to the future.

Consider an agent who:

1. Observes a systematic repetition and regularity between doing a type of act $\mathrm{A}$ in the present and observing the occurrence of a type of event $\mathrm{E}$ in the past.

2. Can find no causal explanation for that type of past effect $E$ by going back to previously occurring events prior to $\mathrm{E}$.

3. Can find no ordinary causal relation between the past type of event $\mathrm{E}$ and the present type of act $\mathrm{A}$ that proves the type of event $E$ to be the cause of the of act of type A.

4. Can find no incidents in which he tries to do A but he fails, i.e., type A of action is always in his power to be performed.

Such an agent will have a good reason for believing that his intention to bring about the type E of event, by way of performing type A of act, makes sense. But more importantly, such an agent will have a reason to suspect any informant that tells him about the nonoccurrence of the past type of event $\mathrm{E}$ when he has the intention to bring it about by performing A. But this result has a specific importance when it comes to the ignorance condition, because the agent in this case can't be said to be ignorant of the occurrence of the past type of event E; in fact, he can't be ignorant of the occurrence of the past type of event $E$, because the occurrence of the past type of event $E$ will fall under his knowledge in intention, which he will trust more that the ordinary ways of being informed about the past if the previously mentioned conditions are fulfilled.

Suppose that for the last four years I observed that every time I make a phone call from the department, I hear about a heavy snowing in my country that starts exactly two hours before the time I made my call. Suppose that being aware of the awkwardness of my 
belief I tried everything to make sure that I have a reason to believe that it is really my calling from the department what is causing the previous snowing, even in times when it is not really supposed to snow there. After trying almost all possible ways to check my belief, I arrive, after four years, at a point where I believe that making a phone call from the department causes a previous snowing. I try all Dummett's conditions and I find a perfect match:

First, calling is always proven to be something that I can do and there are no cases where I try to make the phone call but I couldn't.

Second, I couldn't find any other ordinary causal explanation for the snowing in times and places where snowing is not even expected.

Third, there is a systematic repetition and regularity between my calls and the snowing.

Fourth, snowing in my country can't be explained as the cause of my calls.

In this case, I would have a reason to believe that I am causing it to snow 2 hours before I make phone calls by way of making those phone calls. Furthermore, after I reach my belief in the consistency of trusting my backward causal ability to affect the past, and after checking the fulfillment of the four conditions, I can't even be considered to be ignorant of the past occurrence or nonoccurrence of the past snowing. Because even in cases where ordinary ways of being informed about the past events are not available, I can still appeal to my knowledge in intention as directed to the past. I can simply claim that I have the ability to know about the snowing before I hear about that from any one, because my intention to bring about that snowing by way of making a phone call makes me no more ignorant of the snowing. Of course, what I am claiming sounds strange, but remember that this is something that I tried for four years to check and it was proven to be working all the time. I might even start using my discovered new ability to call my friends back home and tell them about the snow even before they say anything. 
In short, in cases where the agent establishes a backward causal belief about the past, the agent can't really be said to be ignorant about the occurrence of the past event, since the concurrence of that past event lies in the agent's knowledge in intention as applied to the past.

But let's suppose that an agent, whom I will refer to as 'Dummett's agent', was informed about the nonoccurrence of the past event which he intends to bring about. Would that motivate him to give up his attempt to bring about that event? No, because in this case Dummett's agent will take the position of any ordinary agent who intends to bring about some effect in the future and is informed about the nonoccurrence of that event. He will simply suspect the information he has got about the nonoccurrence of the event in question, instead of suspecting his knowledge in intention.

Dummett's agent who is informed about the nonoccurrence of the past event that he intends to bring about will not lose his motivation to bring about that event; rather, he will interpret the information as being false and not trustworthy, simply because the occurrence of that type of event lies in his knowledge in intention.

In "Bringing about the past" Dummett says about an agent who is informed of the nonoccurrence of a past event $\mathrm{E}$ which he thinks to be the effect of a present action A,

Now he need not really deny that learning, in the ordinary way, that E has not occurred makes it at all more probable that, if he tries to perform A he will fail. He may concede that it makes it to some extent more probable, while at the same time maintaining that, even when he has grounds for thinking that $\mathrm{E}$ has not occurred, his intention to perform A still makes it more probable than it would otherwise be that $\mathrm{E}$ has in fact occurred. The attitude of such a man seems paradoxical and unnatural, but I can't see any rational considerations which would force him out of this position. (Dummett 1980: 349)

But what if the agent was not merely told about the nonoccurrence of the past event in question? What if he has seen or experienced the nonoccurrence of the past event himself; would that change the case? In other words, what if we replaced others' testimony by memory as another way of knowing the past? Would this kind of replacement change the argument in favor of allowing at least a weaker version of the ignorance condition? A version that requires the agent to have no "memory-based" access to the occurrence or the nonoccurrence of 
the past event to rationally believe in bringing about that past event by way of doing something in the present. To anticipate what will be presented, the answer to this possibility is no. I argue that the agent who depends on memory as one way to objectively know about the past, similar to the agent who depends on others' testimony, doesn't need to be ignorant - either partially or fully — about the past to believe in the consistency of backwards causation. To explain more, let's consider the case that Dummett suggested as his typical faithful believer in backwards causation, or what is known as "the dancing chief" (Dummett 1980: 343).

In "Bringing about the past", Dummett asks us to imagine a tribe that has a specific custom; every second year the young men of the tribe are sent on a lion hunt to prove their manhood; during this ritual they travel for two days, hunt lions for two days, and spend two days on the return journey. Observers accompany them in their trip to report to the chief upon their return whether the young men were brave or not. The tribe's whole causal beliefs are different from ours; they hold that some ceremonies performed by the chief have the ability to influence weather, etc; but what is important to be remembered is that these ceremonies are not to be taken as related to gods of any kind at all. Now, while the young men are away from the village, the chief performs ceremonious dances intended to cause the young men to act bravely.

Let's suppose that the chief continues to perform these dances for the whole six days that the party is away. His act can be considered as a case of an act performed for the purpose of bringing about the past.

Now, let's apply the distinction between memory and others' testimony, as two distinguished ways to know about the past, to examine whether the distinction will require the agent at least to have no "memory-based" knowledge of the occurrence of the past event to have a rationale for believing that he can bring about that type of past event by causing its causes in the present. But first, let's reinvestigate what would knowledge of the past as based on others' testimony be like in this case. As I mentioned earlier, an agent who has a belief based on a long experience, and fulfills all the conditions specified by Dummett for holding a backward causal belief, doesn't depend any more on other ordinary ways of being informed about the past that go beyond his knowledge in intention. As Dummett explains, the 
chief already believes on the basis of his past experience that his act of dancing is able to bring about the previous bravery of the young men; he is not testing a new causal hypothesis by trying to dance and then watching what will happen, or what the reports would tell him about what had happened.

Now, whether the chief is justified in holding such a belief or not, or even what grounds he has for holding it is another issue that is of no importance here. What matters is that what really causes the chief to dance during this particular hunting trip made by the young men is his belief that his dancing will cause the young men's previous brave behavior.

What should be remembered here is the fact that he is not trying to test what would his dance accomplish or how can his dance causally affect the past behavior of the young men; rather, he is already convinced that there is a causal connection between his dancing and their past brave behavior. This means that Dummett's chief, already convinced of his backward causal powers, will simply interpret any reports of the young men not being brave as false, since his rationale not to believe those reports after he danced successfully as usual and as he did — let's say for the last 20 years — will be stronger than the rationale to believe such kind of reports. The case of ignorance as based on others' testimony is then ruled out. The bravery of the young men is a knowledge already acquired by the chief as he dances to bring that previous bravery about.

However, what about knowledge as based on memory? Does it form a case different from the previous case? Practically speaking, what if the chief decides to accompany the young men in their hunting trip instead of waiting patiently for the reporters to come back and tell him about what had happened? Would the case be any different? Would the chief lose his rationale in believing in his ability to cause past brave behavior among the young men, simply because of observing the young men acting differently? On the opposite, the chief who accompanies the young men won't be that different from the chief who waits for the reports to be sent to him. Because while the second will interpret what is said to him as false, the first will interpret what he observes by himself as false. He might for example interpret what he observes as mere hallucinations, day dreams, tricks played by the young men, etc, simply because in both cases the 
chief's deeply rooted belief, as based on his long experience, goes beyond what can be falsified by whatever can be said or even observed.

The chief's belief in such a strong causal connection that doesn't seem to need much further investigation is not that odd, although it might look like that. It is a common feature of our epistemic system, because we, as human beings, don't repeatedly reinvestigate our already established causal beliefs; rather, we just take them for granted. In fact, any advancement in our human knowledge would be impossible if reinvestigating all causal beliefs that we assert is required each time we assert them. Our everyday behavior tells a different story; we investigate our causal beliefs only as we are establishing them, but when they are already established, we only apply them. For example, the teacher who wants to explain the law of gravity to his students will simply drop the pen from his hands, not to see where the pen will go, or to examine if the pen will go to the ground or not, but to show his students that the pen will certainly land on the ground in seconds. The teacher in this case is not interested in examining his causal belief as much as he is interested in demonstrating it; he might not even feel the need to look at the pen while it is falling to the ground; he might simply drop the pen and turn his face to his students. ${ }^{1}$ In short, already existing causal beliefs, when transferred into new cases, don't depend on observation, because observation takes place only when the causal belief is still to be established. However, it is very important for my argument to keep in mind that what I mean by casual connections, are those causal connections taking place between types of events and not simply causal connections taking place between events.

However, this has been addressed early in the four conditions required of an agent to rationally believe in the consistency of backwards causation. Therefore, what matters in the case is the belief that dropping things will cause them to fall down, and not the concrete individual case of dropping a pen. Therefore, the first instance of a case to opposite, where the teacher fails to cause the pen to fall to the ground by dropping it, won't immediately motivate him to move from the mental statues of transferring already existent causal

\footnotetext{
${ }^{1}$ As I made clear earlier I am limiting my argument to cases in which the cause is the necessary as well as the sufficient reason for bringing about the effect.
} 
beliefs to establishing new causal beliefs; simply because what matters are not events but types of events. The clash between the already established causal belief that the teacher holds and the temporary impossibility — that he observes for the first time — is not to be understood as a clash between two causal beliefs per se, and better to be understood as a clash between a causal belief, already established between types of events, and a causal connection to the contrary between two events; in other words, the teacher's observation to the causal connection between throwing the pen and the pen's floating in the air will not be evaluated by him the same way he evaluates the causal connection between throwing the pen and the pen's falling down to the ground. Simply, because the first case mentally represents a mere connection between events, while the second represents an already established causal belief based on a connection between types of events. One can easily predict that it will be a long way before this isolated causal connection, between the two events of throwing the pen and its floating in the air, can be mentally affirmed and established, and only then it can become transformable to new cases.

In fact, establishing causal beliefs is an ongoing process that only starts by events and doesn't fulfil until it forms a belief in a casual connection between types of events. Similarly, the chief who believes in his ability of bringing about a past bravery of the young men had to go through a long process of repeatedly experiencing an actual ability of bringing about past bravery by way of dancing over the years. As a result, the chief's first response to the denial of his long term causal belief — as taking place between types of events - will be to deny what the observation from one event says.

Of course, my argument doesn't mean the total negation of any role of observation after the causal belief is established. As a matter of fact, repeated cases of counter examples can eventually motivate one to suspect the reliability of his/her already established causal beliefs. In the long run, this suspension and reevaluation of one's causal beliefs can end by forming contrary new causal beliefs. However, what is important to keep in mind, is the fact that forming the new causal beliefs would require going through a totally new process of establishing those new opposite causal beliefs.

In all cases, as we have seen, observation doesn't play much of 
a role in applying previously established causal beliefs, because it is taken for granted. It starts to play a role only if it repeatedly starts giving results opposite to what is expected, and even in this case, the process of suspecting the already established causal belief and forming a new causal belief is a long process that a single observation can't suffice to bring about.

How does that affect the ignorance condition? Well, as I argued before, observation is an essential step for establishing new causal connections; more precisely speaking, for the mental affirmation of the existence of causal connections. But after the causal connection is established, observation is no more needed, at least in the way we understand causal connections and deal with them. As with the case of the teacher, the chief who already believes in a causal connection between his present dancing and the past brave behavior of the young men doesn't even need to bother himself to make any effort to know whether the young men have been brave or not, because what matters for him is not the occurrence of the effect itself, but the soundness of the whole causal belief he had. This is because the act of his dancing is not an act made for the purpose of discovering or establishing a new causal connection, on the contrary, it is an act of applying an already affirmed causal connection to other cases.

One might object that the ignorance condition applies before and not after the chief dances. It applies when the chief knows that the young men have been brave before he dances or when he knows that the young men have not been brave; consequentially, what we really need is a discussion of the chief's motivation and rationale to dance after he knows about previous bravery, and before he performs any dances. Now, the two cases can be easily evaluated if we avoid a confusion that might take place here between two causal beliefs,

(a) if I dance I can cause previous bravery of the young men.

(b) if I dance I can cause the bravery of the young men.

The chief's basic causal belief is (a) and not simply (b). For example, in the case where the chief knows about the previous bravery of the young men, what he is informed of is the previous bravery which he believes to take place because of later dancing, and not simply because of dancing. Therefore, even after knowing that the young men have 
been brave, he will still be motivated to dance, because what he believes in is the effectiveness of his later dancing, and not merely his dancing. The chief who discovers that the young men have been brave, even before he dances, would still be motivated to dance, because according to his belief - it is his later dancing what really causes the previous bravery of the young men. Here, it is always important to remember that according to the chief's causal belief, the bravery of the young men is a previous effect of a lately occurring cause.

Let ' $\mathrm{B}$ ' stand for the young men's being brave and ' $\mathrm{D}$ ' stand for the chief's dancing. Let's suppose that the chief was able to know about the brave behavior of the young men in one way or another; let's say that one reporter stood on a top of a mountain and signaled to him informing him of the bravery of the young men even before he started dancing. How can one explain what will take place in this case? When the chief is informed of the bravery of the young men what he is informed of is the previous bravery, while his belief which forms the real cause for his act of dancing is the causal belief that later D causes previous B and not merely previous B; so when the chief is asked for example by his grandson, "why do you dance after you have already been informed of the bravery of the young men?" he will simply say, "because my dance is the cause of the bravery of the young men". In other words, he will refer in his answer to his belief in the causal law; he will not refer only to B, because basically it is his belief in the causal law what motivates him to dance. But, if his grandson was still curious and he asked him another question, "but why do you still have to dance while you know that the young men have already proven their bravery, aren't you wasting your time by doing that?" Probably the chief would answer him by saying, "Well, because it is this dance that I am going to perform that has caused them to be brave, if they have really been brave. If the young men have been brave they must have been brave only because I will dance now."

To draw an analogy with the future; suppose that the chief, instead of believing that his later dance causes the previous bravery of the young men, believes that drinking a special drug can keep him from getting sick. Suppose the chief - in an attempt to stay healthy - makes sure to drink this drug every day before breakfast. Now, let's imagine that one day his curious grandson asks him the question: "why do you take that drug every day?" Then the chief would 
probably say something like: "because I want to be healthy". What if the curious grandson was not satisfied and insisted on getting a better answer by saying: "But you are healthy!"? At this point of the dialogue, the chief would probably say something similar to what he says in the case of defending his dancing, because he might say something like: "but taking the drug is what makes me healthy".

Actually, changing causal beliefs after they are already established is not as easy as some might think, because a new process of forming the opposite causal beliefs would be needed before one can be able to assert them. I argued that the chief who is informed of the occurrence or the non-occurrence of the previous effect will still have a rationale to believe that he can explain the previous effect by later causes; furthermore the chief who after dancing is informed of the non-occurrence of the previous effect has a rationale to suspect what he is told or even what he observes, because he will have two contradictory beliefs, first: his belief in the law that later D causes previous $\mathrm{B}$, and second the belief that previous B did not occur even though later D occurred. Therefore, he must abandon one of the two beliefs. ${ }^{2}$

The chief's belief in the causal law if already established from the past - as is the case with any causal belief — will no longer need to appeal to any observation to reestablish it; if the chief was sure of the truth of the law, then he would hesitate not to dance even after hearing reports about B because, if the previous bravery was the outcome of his later dancing, then not dancing after he is informed of their bravery will end up in one way or another in the young men's not having been brave. He might think that, if their bravery is caused by his later dance, and he was sure of that causal relation, and he didn't dance after he hears about their previous bravery, the consequence will be not believing that the young men were brave, because if the causal belief is what provides him with the rationale for believing that the young men have been brave, not dancing will leave him without any reason for believing in the occurrence of B. It might be the case that he doesn't dance and the reporters tell him, after coming back from the trip, that the young men have been brave, but he might sim-

\footnotetext{
${ }^{2}$ Here I am considering the case where later $\mathrm{D}$ is a sufficient as well as a necessary cause of $\mathrm{B}$, to eliminate the complexity from having other equally effective causes.
} 
ply not believe the reporters; he might think that the reason he has not to believe the reporters, namely, not dancing, is stronger than the reason he has to believe them, namely, their testimony.

In other words, in case the chief didn't dance after he has been informed about the previous behavior of the young men, he will start to suspect B itself instead of suspecting the causal law, because as I have said before, the chief is $100 \%$ sure of his belief in the causal law 'later D causes previous B'. The observation that B is not enough for him to suspect the causal law; consequentially, he will be left only with one option, namely, to suspect the occurrence of B. Similarly, our confident chief will not be motivated to suspect the occurrence of the later dancing as he witnesses a cowardly behavior of the young men, the same way he doesn't suspect the previous bravery; for example, he will not say to himself as he observes the cowardly behavior of the young men, "probably I will not be able to dance this time, probably I will slip on a banana peel"; this is because his observation is merely based on one event, while his causal belief connects types of events and not events. In other words, the chief will have a rationale to suspect his ability of dancing if his belief was 'This later dance D will case previous bravery B'. But his belief is more like: 'Later D causes previous B' or more accurately speaking, his belief is more like: 'Later type of D causes previous type of B.'

In his objection to Dummett's argument in favor of the consistency of backwards causation, Gorovitz in his paper "Leaving the past alone" wrongly — as I discussed before — ascribed to Dummett the agent's ignorance of the occurrence of the past event as a condition for the consistency of his believing in backwards causation. But furthermore, he discussed a case he claimed that Dummett omitted. It is the case where the chief and instead of waiting for the reporters to come back and inform him about the behavior of the young men insists on witnessing the hunt himself. In this case Gorovitz concludes no dance will be necessary. He asserts this by saying, "I conclude that if the chief witnesses the warriors being brave, no dance is necessary" (Gorovitz 1964: 368).

He describes this case by saying,

In Dummett's example, various experiments are described that are designed to show the chief to be in error in his beliefs. These experiments all fail. But there are a few more which Dummett did not consider. For 
example, instead of letting the chief remain at home while the warriors hunt, only to cause after their return their having been brave on the hunt, let us insist that the chief himself witnesses the hunt. Now there can no longer be any question of lying reporters who try to deceive the chief, only to be discovered when he dances. The chief will himself observe the cowardice or bravery of the men. Then if they were brave, he will of course have no need to dance. (Gorovitz 1964: 368)

But taking into consideration my distinction between transferring already established causal beliefs and establishing new causal beliefs we can find a way to answer the case designed by Gorovitz. Because the chief who already believes that his later dancing always causes previous bravery of the young men will continue trusting his always-trusted belief even if he witnessed the hunt himself. In fact, the difference in the way he gets the opposite information to what he believes in will not be immediately trusted by him, his being informed about the cowardly behavior of the young men before he starts dancing or even his witnessing himself the cowardly behavior before he starts dancing. This will not shake his belief in the causal law, because the chief who already believes that his later dance causes previous brave behavior is not even depending anymore on what he is informed about, or what he witnesses himself to confirm his beliefs. In both cases he will find a way to interpret what he is informed about or what he sees in way that fits his causal beliefs. The stronger and better established his beliefs are, the less the chief will take what he sees or hears about to be reliable enough to change his beliefs. The chief who believes that his later dance causes previous bravery will simply interpret all reports about the non-brave behavior of the young men as being false in case he was informed about that after he dances, but in case he was told about the non-brave behavior of the young men before he dances, this will enforce his belief that the bravery of the young men is conditioned by his dancing. Similarly, Gorovitz's chief, who, unlike Dummett's chief who stays home and waits for the reporters to come back, insists on witnessing the hunt himself, will interpret the behavior he witnesses either cowardly or brave, in a way that fits his causal beliefs. This means in case the chief didn't dance yet and he witnesses a cowardly behavior of the young men, this will insure his belief that he should have danced to make them behave bravely, and his belief will be asserted; but in case the 
chief witnesses a brave behavior of the young men before he dances, he will simply interpret that as false. He will accuse the young men as acting in a way to deceive him or being involved in a conspiracy against him, or he might interpret what he witnesses as false and only as hallucinations because of his getting old. In short, Gorovitz's dancing chief is not that different from Dummett's chief, and the case Gorovitz designs doesn't necessarily end as he claims by causing the chief not to dance.

To sum up what has been said until now, the chief's rationale for dancing is his belief in the causal law: later D causes previous B; this causal belief, like any other causal belief that one might have, is formed according to previous observation or previous set of observations of a regularity that takes place between previous $\mathrm{B}$ and later $\mathrm{D}$, or it might be based on testimony, because as said before, it might be the case that the act of dancing to bring about the previous bravery of the young men is a tradition that the chief inherited from his father, who inherited it from his father, and so on. What matters is that after the causal belief is already formed, the human mind usually moves to another step, which is applying this same already existing belief as constructed in the past to new cases in the present and even in the future, without much investigation.

In the case of the dancing chief, if he has any causal belief at all, he might have one of the two: either later D causes previous B, or later $\mathrm{D}$ causes $\sim$ previous $\mathrm{B}$, according to what he had concluded from his previous observations. Now, if the chief believes that later D causes previous B, then his knowledge of the occurrence of later B will not affect his act of dancing, because he thinks that the occurrence of previous B is caused by the later act of dancing that he will perform. Therefore, the occurrence of previous B will be interpreted by him as being not true if it was not followed by its cause, D. Here, what we should always remember is that if the chief really has the causal belief if later D causes previous B, then he will take it for granted that the occurrence of previous $\mathrm{B}$ must be conditioned by the later occurrence of $\mathrm{D}$; he will not be examining what will happen after previous $\mathrm{B}$ takes place, because if he was only trying to examine the relation between previous B and later D, then he can't be said to have an established causal belief of the kind later D causes previous B, as gained by his previous experience, and this is not the case of the chief as we 
know it and as Dummett originally presented it, i.e., as a case of an already existing causal belief of the kind if later $\mathrm{D}$ causes previous $\mathrm{B}$.

In short, the agent needn't really be ignorant of the occurrence of the past event to have a rationale for believing that there is no logical contradiction in believing that this event can be brought about by doing something in the present; this ignorance applies equally to all ordinary ways of being informed about the past, wither via memory or others' testimony. But more importantly, the agent who holds such a belief can't really be said to be ignorant of the occurrence of the past event, because the occurrence of the past event will fall under his knowledge in intention. The difference is only that this knowledge in intention is directed towards the past instead of being directed towards the future.

Dummett draws this conclusion in "Bringing about the past" by saying,

My conclusion therefore is this. If anyone were to claim, of some type of action A, (i) that experience gave grounds for holding the performance of A as increasing the probability of the previous occurrence of a type of event E; and (ii) that experience gave no grounds for regarding $A$ as an action which it was ever not in his power to perform, then we could either force him to abandon one or other of these beliefs, or else to abandon the belief (iii) that it was ever possible for him to have knowledge, independent of his intention to perform A or not, of whether an event $E$ had occurred. (Dummett 1980: 349)

Let's read what Dummett had to say about that in his paper "Causal loops",

Originally we made the natural assumption that we could, on occasions, know whether or not F had occurred independently of our intentions - precisely the assumption that cannot be made in relation to any future event which we believe ourselves to have the means of bringing about or of preventing. It was because we made that assumption that we were able to establish the correlation between the performance of $\mathrm{B}$ [present action] and the previous occurrence of $\mathrm{F}$ [past event]. It was also because we made this assumption that we took it for granted that there was no point in trying to bring it about that $\mathrm{F}$ occurred when we have clear evidence that it did not. Although we placed sufficient reliance on the correlation between $\mathrm{B}$ and $\mathrm{F}$ for the performance of $\mathrm{B}$ to count as increasing the probability that $\mathrm{F}$ occurred in cases in which we had no evidence of an ordinary kind about whether it did or not, we trusted such evidence so much more than we trusted the correlation 
that the performance of B did not significantly affect our estimate of the probability of F's having occurred in cases in which we possessed that evidence, even though we knew that evidence for a past event can sometimes prove mistaken. (Dummett 1996: 361)

For Dummett, the hindrance that prevents us from believing that the concept of affecting the past can be made sense of lies in our belief that knowledge in intention can be directed towards the future but can't be directed towards the past, due to the belief that knowing past events can have other more objective informing resources other than our knowledge in intention. But this is a mere psychological effect of having memory and not having foreknowledge, and in some special cases, where our experience repeatedly keeps telling us that performing certain type of actions in the present has been associated with the occurrence of certain types of events as previously observed to be taking place in the past, should be sufficient to make us take our knowledge in intention when directed to the past as being as reliable as our knowledge in intention as directed to the future.

One challenging question that one might be motivated to ask in response to my interpretation to Dummett's view on the ignorance condition is the following: should knowledge in intention be considered as knowledge? What I have asserted is that the agent who believes in the consistency of the idea of attempting to bring about a past type of event by doing something in the present can't be said to be ignorant of the past type of event, because that type of event falls under his knowledge in intention. The same is true for an agent who tries to cause something in the future by doing something in the present, his knowledge of that thing can be said to fall under his knowledge in intention. This means that, in both the cases of the future and of the past, the agent can't be said to be totally ignorant of the type of event he is trying to bring about. But what if knowledge in intention is not to be considered as knowledge? Here in my response I need to make it clear that, for Dummett, knowledge in intention is not to be considered less objective than knowledge as acquired by ordinary ways of being informed, and any reading that fails to appreciate this would end up misinterpreting Dummett on this point. However, the objectivity of knowledge in intention might be more easily defended in the case of the future, where this knowledge not only is acknowledged by Dummett, but also acknowledged 
as a kind of knowledge that can contradict the other ordinary ways of knowing the future, such as prediction as based on causal laws. As Dummett makes clear, an agent who has the intention to bring about some effect in the future, that he believes to be able to bring about, can't fulfill the request to bring about that effect, when he knows by ways other than his intention that this effect will not take place, because his knowledge in intention and his knowledge in prediction will contradict each other, and he will eventually have to appeal to one of them. This appeal makes it apparent that knowledge in intention is not to be considered as less objective than knowledge as based on prediction in the case of the future. In "Bringing about the past" Dummett says,

If someone believes that a certain kind of action is effective in bringing about a subsequent event, I may challenge him to try it out in all possible circumstances: but I cannot demand that he try it out on some occasion when the event is not going to take place, since he cannot identify any such occasion independently of his intention to perform the action [...] I cannot be asked to perform the action on some occasion when I believe that the event will not take place, when this knowledge lies in my intention to prevent it taking place; for as soon as I accede to the request, I thereby abandon my intention (Dummett 1980: 344)

This means that knowledge in intention plays a role that is no less objective than knowledge as based on prediction when both are applied to future circumstances, and of course the term 'objective' as applied to the way we know the future is relative since we don't have foreknowledge. Now, if knowledge in intention is applied to the past the way it is applied to the future, the result would be in favor of the argument for the consistency of backwards causation; because in some cases, as Dummett makes clear, the intention to cause the past event forms a ground for believing in the occurrence of that event, similar to what takes place regarding future events. Dummett says (for a previous event $\mathrm{F}$ and a later act $\mathrm{B}$ ) "the intention to do B becomes itself a ground, in some cases, for supposing that $\mathrm{F}$ has occurred" (Dummett 1996: 369).

But this is not the way things tend to be, because while we separate our knowledge in intention from our knowledge of the occurrence of past events, we find out knowledge in intention hardly to be separable from our knowledge of the occurrence of future events. 
This is because, as asserted before, we have memory but we don't have foreknowledge. But this doesn't mean that knowledge in intention is to be considered less objective than knowledge as based on prediction when both are applied to the future. Dummett says,

The difference between past and future lies in this: That we think that, of any past event, it is in principle possible for me to know whether or not it took place independently of my present intentions; whereas, for many types of future event, we should admit that we are never going to be in a position to have such knowledge independently of our intentions (if we had foreknowledge, this might be different). (Dummett 1996: 349)

What is still important to be stressed here is to make a distinction between the natural attitude of the agent after objectively being informed by the ordinary ways of the occurrence or the nonoccurrence of past events, and what might be his rational attitude. Because, as Dummett makes clear, it is the natural response of us to lose our motivation to perform an action as designed to bring about previous types of effects after being informed of their nonoccurrence. But the non-naturalness of the response of a person who continues trusting his knowledge in intention to perform the action, more than trusting the ordinary objective way of being informed, doesn't imply the logical inconsistency of such a response. In "Bringing about the past", as we have read, Dummett describes the attitude of a person who will continue trusting his knowledge in intention more that the ordinary way of being informed as being "paradoxical and unnatural to us" even if he can't see any "rational considerations which force him out of this position" (Dummett 1980: 349).

In "Causal Loops" Dummett explains clearly the psychological reasons that prevent us from believing in the consistency of backwards causation. He clarifies the fact that these reasons are not based on logical or metaphysical grounds as he says,

Thus what stands in the way of our supposing it rational to do anything in order that something else should previously have occurred is not the logical fact that the event in question has already either occurred or not occurred, or the metaphysical status of the past as fixed, in contrast to the fluid condition of the future, but our assumption that, of any past event, we may have evidence for its occurrence or nonoccurrence whose strength can be estimated independently of our intentions. This assumption is, of course, based, not only on causal connections from 
earlier to later, but on the absence of any comparable connections in the reverse direction - that is, connections that we might use to attempt to bring it about that certain events had previously occurred. Just because the assumption is deeply engrained in us, we should feel the strongest psychological resistance to recognizing any such connection; but, were we to recognize one; we should have, to that extent, to modify that assumption. This would profoundly alter our conception of evidence about the past, but it would not produce conceptual chaos (Dummett 1996: 363)

In making a distinction between causes that precede their effects and causes that follow their effects (quasi-causes), Dummett refers to the fact that quasi-causes appear redundant when we know that their effects have taken place. "We must compare with the effectiveness of quasi-causes the effectiveness of causes. A quasi-cause appears redundant when we know that the wished-for effect has taken place" (Dummett 1980: 331). The word 'appear' is not to be overlooked here because it is not the case that knowing the occurrence of past effects makes the quasi-causes redundant; it only makes the quasicauses appear redundant.

\section{Conclusion}

In this paper I defended the argument for the consistency of believing in backwards causation against the objection from the ignorance condition. This objection, I argue, is based on a misinterpretation of Dummett's proposal. Therefore, in my defense, I presented an interpretation of Dummett's position in which I tried to clear up the confusion regarding the ignorance condition as a condition wrongly believed to be required by the agent to believe in the consistency of backwards causation. In my argument, I defended the view that, not only the agent doesn't need to be ignorant of the occurrence of the past event to have a rationale for believing in the logical consistency of attempting to bring about the occurrence of that past event by doing something in the present; in addition, such an agent can't be said to be really ignorant of that event, as long as bringing about that event lies in his knowledge in intention. I depended in my argument on the distinction that can be applied to both future and past events between two kinds of knowledge: knowledge in intention and 
knowledge as acquired by ordinary ways of being informed. ${ }^{3}$

$$
\begin{array}{r}
\text { Abla Hasan } \\
\text { University of Nebraska-Lincoln } \\
\text { Office 1025 OLDH } \\
\text { Modern Languages and Literatures } \\
1111 \text { Oldfather Hall } \\
660 \mathrm{~N} \text { 12th St } \\
\text { Lincoln NE 68588-0315 } \\
\text { abla.hasan@unl.edu }
\end{array}
$$

\section{References}

Dummett, Michael. 1980. Bringing About the Past. In Truth and Other Enigmas. Harvard University Press.

Dummett, Michael. 1980. Can an Effect Precede its Cause? In Truth and Other Enigmas. Harvard University Press.

Dummett, Michael. 1996. Causal Loops. In The Seas of Language. Oxford University Press.

Gorovitz, Samuel. 1964. Leaving the Past Alone. The Philosophical Review 73 (3): 360-371

Hanoch, Ben-Yami. 2007. The Impossibility of Backwards Causation. The Philosophical Quarterly 57 (228): 439-455.

Peijnenburg, Jeanne. 2006. Shaping your own Life. Metaphilosophy 37 (2): 240-253.

${ }^{3}$ I am grateful to Prof. Edward Becker, University of Nebraska-Lincoln, for his valuable discussions. 
